\title{
Hydatidiform moles among patients with incomplete abortion in Mwanza City, North western Tanzania
}

\author{
Bernard Kitange ${ }^{1}$, Dismas Matovelo ${ }^{1,2}$, Eveline Konje ${ }^{3}$, Anthony Massinde ${ }^{1}$, Peter Rambau ${ }^{4}$
}

1. Bugando Medical Centre, Obstetrics \& Gynecology

2. Catholic University of Health \& Allied sciences, Obstetrics \& Gynecology

3. Catholic University of Health and Allied sciences, Epidemiology

4. Catholic University of Health \& Allied sciences, Pathology

\begin{abstract}
Background: Prevalence of hydatidiform mole is not clearly defined, partly because most studies have reported different prevalence rates from different regions. However, there is no previous study that has determined the prevalence and associated risk factors of HM among patients with incomplete abortion evacuated at Bugando Medical Centre (BMC) and Sekou Toure Regional Hospital (STRH).

Methods: A total of 180 patients with incomplete abortion were enrolled between February 2013 and April 2013. The prod- ucts of conception were collected and analyzed using Haemotoxylin and Eosin staining technique for hydatidiform moles. Results: One hundred and eighty patients with incomplete abortion scheduled for uterine evacuation agreed to participate in this study. The overall prevalence of HM was $12.8 \%$. Majority of patients (27.5\%) with HM were those aged below 20 years. No significant association was observed with risk factors such as parity, contraceptive use, previous abortion and blood group.

Conclusion: The prevalence of HM (12.8\%) was high and age between 15-20 years was the only significant associated risk factor with the presence of HM among patients with incomplete abortion. Therefore, we recommend submission of evacuated products of conception for histopathological analysis to minimize missed opportunity.

Keywords: Prevalence, hydatidiform mole, incomplete abortion, Mwanza, Tanzania.

DOI:

http://dx.doi.org/10.4314/ahs.v15i4.5

Cite as: Kitange B, Matovelo D, Konje E, Massinde A, Rambau P. Hydatidiform moles among patients with incomplete abortion in Mwanza

City, North western Tanzania. Afri Health Sci. 2015;15(4):1081-6. bttp://dx.doi.org/10.4314/abs.v15i4.5
\end{abstract}

\section{Background:}

Hydatidiform mole (HM) is a spectrum of abnormal gestations arising from villous trophoblast associated with pregnancy ${ }^{1}$. HM has two histological types, including partial hydatidiform mole (PHM) and complete hydatidiform mole $(\mathrm{CHM})^{2}$. $\mathrm{HM}$ is among gestational trophoblastic disease (GTD) and others include chori-

\footnotetext{
Corresponding author:

Dismas Matovelo,

Catholic University of Health

\& Allied sciences,Obstetrics

\& Gynecology;

Bugando Medical Centre,

Obstetrics \& Gynecology

Email:magonza77@yahoo.co.uk /

magonza@bugando.ac.tz
}

ocarcinoma and placenta site trophoblastic tumors that arise from villous trophoblast and interstitial trophoblast respectively ${ }^{1}$.

The prevalence of HM varies widely in different regions of the world. Studies conducted in the developed countries (North America, Australia, New Zealand and Europe) show a prevalence of HM ranging from 0.51.1 per 1000 pregnancies whereas the higher prevalence is seen in Asia and Japan, accounting for 2 per 1000 pregnancies $^{2}$. The prevalence of HM in Brazil is $2.2 \%$, South Africa 1.2 per 1000 deliveries and Nnewi, Southeast Nigeria is 0.3 per 1000 deliveries $^{3-6}$. Considering these findings, the prevalence of HM is not universally similar and in some countries the prevalence could be higher. In Tanzania, the prevalence of HM is not known due to the lack of studies investigating this problem. HM has several etiological risk factors and the most established are extreme of maternal age and prior molar pregnancy ${ }^{7-9}$. For instance, the risk of complete mole 
increases three fold for women older than forty years and is much higher in patients with previous history of molar pregnancy ${ }^{10,11}$. Several studies have shown a significant association between HM and abortion. Acaia et al reported that among 93 studied women with repeat- ed abortions 9 were found to have $\mathrm{HM}^{12}$. Moreover, another study by Horn et al evaluating the histology of placenta tissues, reported HM specifically CHM to account for $5.1 \%$ of the causes of spontaneous abor$\operatorname{tion}^{13}$.

Initial clinical findings are commonly not suggestive of the possibility of HM in patients with abortion. The routine histopathological analysis of the evacuated products of conception is often not performed in our settings. This may lead to the possibility of mismanagement of the patients with HM if this condition is missed as the cause of abortion. Therefore, this study was designed to determine the prevalence and associated risk factors of $\mathrm{HM}$ among patients with incomplete abortion evacuated at BMC and STRH in Mwanza City, North Western Tanzania.

\section{Methods}

This was a cross sectional study design conducted at two hospitals namely; Bugando Medical Centre and Sekou Toure Regional Hospital which are situated along the shores of Lake Victoria in Mwanza City. The study involved patients who were admitted at gynecological wards for incomplete abortion between February, 2013 and April, 2013. The minimum required sample size of 163 patients with incomplete abortion was obtained by using Kish and Lesley formula ${ }^{14}$.

\section{Data collection}

We collected information on social demographic and maternal characteristics using a structured questionnaire among women who voluntarily consented to participate in the study. The collected products of concep- tion from 180 participants after evacuation were stored in a container with formalin 10\%. The sample collected was sent to main laboratory at Bugando Medical centre and stained using Haemotoxyline and Eosin staining technique.

\section{Data analysis}

Data entry was done using Microsoft Office Excel 2007 according to the pre codes and analyzed using the STATA version 11. Descriptive statistics were obtained for socio-demographic and maternal characteristics accordingly. Categorical variables were summarized into proportion or percentages, and continuous variables were summarized by mean (standard deviation). We assessed association between HM and categorical variables using chi-square statistical test. Those variables with $\mathrm{p}$-value less than or equal to 0.05 were considered at bivariate analysis for logistic regression. Odds ratio was used todetermine strength of association and was reported with $95 \%$ confidence interval. Level of significance for this study was $5 \%$, therefore $\mathrm{p}$ value of less than 0.05 was considered statistically significance.

\section{Ethical approval}

The study protocol was approved by CUHAS/ BMC ethics review Board with ethical clearance no. CREC/016/2013. Participation was voluntary and informed written consent was sought from each patient prior to enrollment.

\section{Results:}

Of 188 patients who consented to participate in this study, only 180 patients were eligible and were involved in the study. The mean age of participants was 26.9 years. Majority of participants $(78.3 \%)$ were self-refer- ral from home and around $42 \%$ were housewives. More than half of patients $(67.7 \%)$ had primary education level and around $9 \%$ of participants reported being employed

(Table 
Table 1: Social demographic characteristics of the study population

\begin{tabular}{lll}
\hline Characteristics & $\mathbf{n}$ & $\mathbf{( \% )}$ \\
\hline Admission status & 141 & 78.3 \\
Self referral & 39 & 21.7 \\
Referred & & \\
Occupation & 75 & 41.7 \\
House wife & 27 & 15.0 \\
Student & 16 & 8.9 \\
Employee & 62 & 34.4 \\
Businesswoman & & \\
Level of education & 8 & 4.4 \\
None & 122 & 67.8 \\
Primary & 48 & 26.7 \\
Secondary & 2 & 1.1 \\
Post secondary & & \\
Marital status & 21 & 11.7 \\
Single & 140 & 77.8 \\
Married & 17 & 9.4 \\
Cohabiting & 2 & 1.1 \\
separated & & \\
\hline
\end{tabular}

The overall prevalence of HM was 12.8\% (23/180) plete hydatidiform mole (CHM) were 11.1\% (20/180) among patients with incomplete abortion. The prev- and 1.7\% (3/180), respectively with the rest of the paralence of partial hydatidiform mole (PHM) and com- ticipants having a normal placenta tissues (Figure 1).

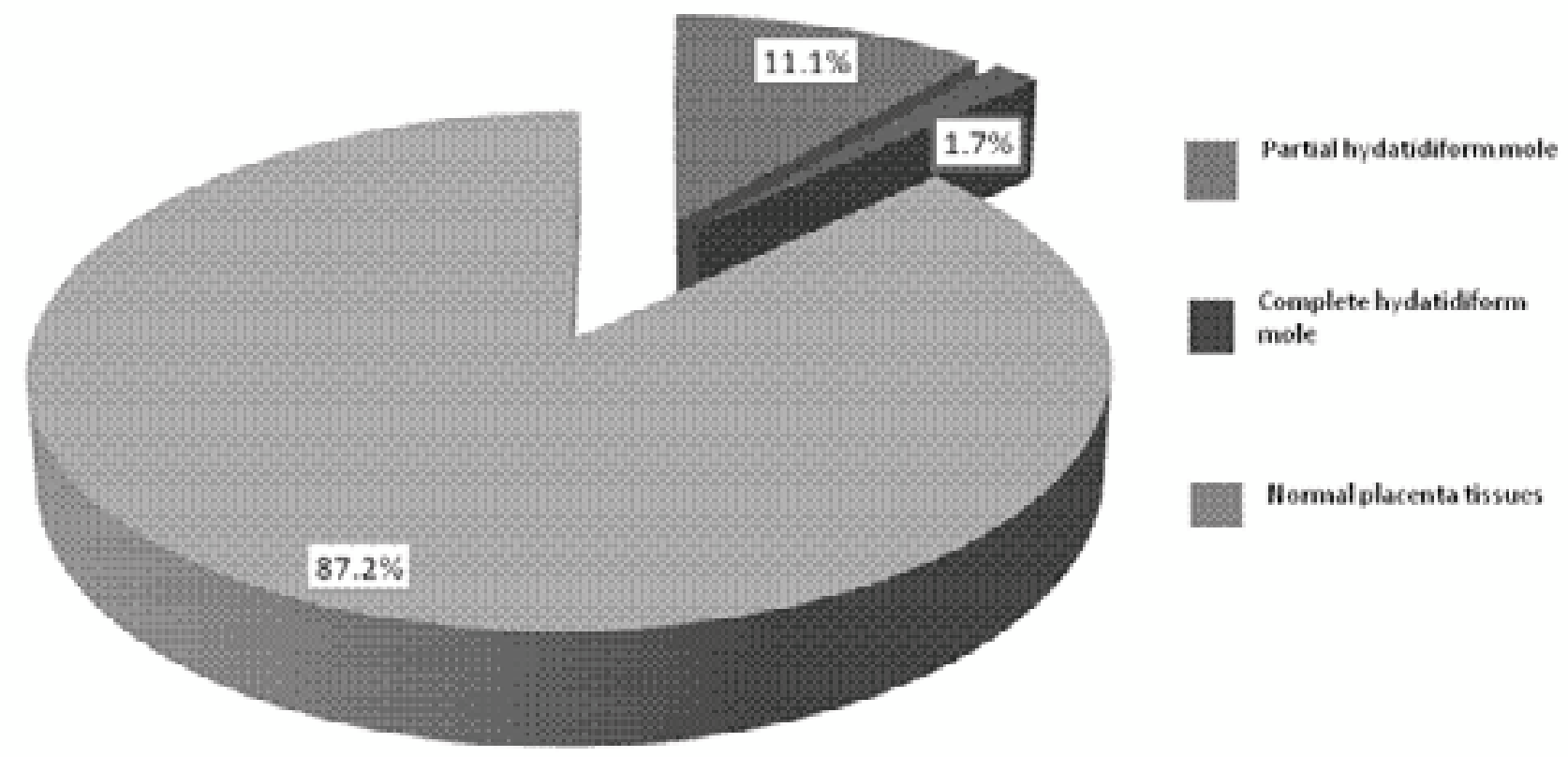

Figure 1: The prevalence of $\mathrm{HM}$ and its pattern 
The prevalence of $\mathrm{HM}$ was observed to be high $(27.5 \%)$ in the age group between 15-20 years, of which $20 \%$ had a PHM while $7.5 \%$ had a CHM and the association was statistically significant $(\mathrm{p}=0.01)$.

Most of the study participants were primiparous 56.1\% and the prevalence of $\mathrm{HM}$ was found to be higher in this group (15.8\%) compared to the multiparous $(9.7 \%)$, and HM was not found among grand multiparous. Moreover, thirteen $(12.9 \%)$ of the primiparous women had a PHM while three (3\%) had CHM although the association between parity and HM was not statistically significant $(p=0.29)$.

Smoking is known to be a risk factor for HM. In this study, only 23 patients reported to have history of cigarette smoking in their lifetime. In this group, the prevalence of $\mathrm{HM}$ was $21.7 \%(5 / 23)$ versus $11.5 \%(18 / 157)$ higher than those with no history of smoking. Quantity and duration of cigarette smoking could not be elicited. Eighty five participants $(47.2 \%)$ had a history of using contraceptives in their lifetime. HM was found in $12.6 \%$ of participants with no history of contraceptive use while $12.9 \%$ was found in participants with history of contraceptive use. Among the participants with no history of contraceptive use, nine $(9.5 \%)$ had a PHM and three $(3.2 \%)$ had a CHM. But no significant association was found between HM and a history of contraceptive use $(\mathrm{p}=0.95)$.

Sixty three $(35 \%)$ participants had a history of previous abortion among whom (14.3\%) had HM, while 117 $(65 \%)$ had no prior abortion but among them $14(12 \%)$ had a HM. Of the 63 participants with previous abortion $5(7.9 \%)$ had undergone induced abortion and 58 (92.1\%) were spontaneous abortion. Nine (15.5\%) of participants with spontaneous abortion were diagnosed to have HM while none of the participant with induced abortion had a HM. However, there was no significant association between HM and history of previous abortion $(p=0.66)$ in this study. None of the participants reported a previous history of HM.

The majority $74(41.2 \%)$ of the participants had blood group 'O', out of whom $12(16.2 \%)$ had HM. Out of 35 participants with blood group 'A', 7 (20\%) had HM followed by participants with blood group 'B' of whom $3(7.5 \%)$ had HM. There was no statistically significant association which was found between HM and blood group $\quad(\mathrm{p}=0.1) \quad$ (Table 2$)$.

Table 2: Prevalence of HM by maternal characteristics for participants at BMC and Sekou Toure Regional hospital

\begin{tabular}{|c|c|c|c|c|c|c|c|}
\hline \multirow[b]{2}{*}{ Variables } & \multirow[b]{2}{*}{ n $(\%)$} & \multirow[b]{2}{*}{ tissue $(\%)$} & \multicolumn{4}{|c|}{ Bivariate } & \\
\hline & & & HM (\%) & OR & $95 \% \mathrm{CI}$ & p value & \\
\hline \multicolumn{8}{|l|}{ Age (years) } \\
\hline $10-19$ & $40(22.2)$ & $29(72.5)$ & $11(27.5)$ & 1 & - & 0.01 & \\
\hline $20-29$ & $78(43.3)$ & $74(94.9)$ & $4(5.1)$ & 0.143 & $0.04-0.5$ & & \\
\hline $30-39$ & $55(30.6)$ & $47(85.5)$ & $8(14.6)$ & 0.449 & $0.16-1.3$ & & \\
\hline$\geq 40$ & $7(3.9)$ & $7(100)$ & $\mathrm{O}(\mathrm{O} . \mathrm{O})$ & - & - & & \\
\hline \multicolumn{8}{|l|}{ Parity } \\
\hline Primiparous & $101(56.1)$ & $85(84.2)$ & $16(15.8)$ & 1 & - & 0.29 & \\
\hline Multiparous & $72(40)$ & $65(90.3)$ & $7(9.7)$ & 0.570 & $0.2-1.5$ & & \\
\hline Grandimultiparous & $7(3.9)$ & $7(100)$ & $\mathrm{O}(0.00)$ & - & - & & \\
\hline \multicolumn{8}{|l|}{ Cigarette smoking } \\
\hline Yes & $23(12.8)$ & $18(78.3)$ & $5(21.7)$ & 1 & - & 0.17 & \\
\hline No & $157(87.2)$ & $139(88.5)$ & $18(11.5)$ & 0.466 & $0.15-1.4$ & & \\
\hline \multicolumn{8}{|l|}{ Contraceptive use } \\
\hline Yes & $85(47.2)$ & $74(87.1)$ & $11(12.9)$ & 1 & - & 0.95 & \\
\hline No & $95(52.8)$ & $83(87.4)$ & $12(12.6)$ & 0.951 & $0.4-2.3$ & & \\
\hline \multicolumn{8}{|l|}{ Previous abortion } \\
\hline $\begin{array}{l}\text { Yec : Induced } \\
\text { Spontaneous }\end{array}$ & $\begin{array}{l}52(35) \\
5(7.9)^{5} \\
58(92.1)\end{array}$ & $\begin{array}{l}54(857) \\
5(100) \\
49(15.5)\end{array}$ & $\begin{array}{l}\text { Oे(1. }(0.0) \\
\text { 9(15.5) }\end{array}$ & A 816 & 0320 & $n 66$ & \\
\hline $\begin{array}{l}\text { No } \\
\text { Previous history of } \mathbf{H M}\end{array}$ & $117(65)$ & $103(88.0)$ & $14(12)$ & 0.816 & $0.3-2.0$ & & \\
\hline $\begin{array}{l}\text { Yes } \\
\text { No }\end{array}$ & $\begin{array}{l}\mathrm{O}(\mathrm{O} . \mathrm{O}) \\
180(100)\end{array}$ & $\begin{array}{l}\mathrm{O}(\mathrm{O} . \mathrm{O}) \\
157(87.2)\end{array}$ & $\begin{array}{l}\mathrm{O}(\mathrm{O} . \mathrm{O}) \\
23(12.8)\end{array}$ & $\overline{1}$ & - & & \\
\hline $\begin{array}{l}\text { Blood groun }(\mathbf{R h}+\mathbf{v e}) \\
\text { A } \\
\text { B } \\
\text { AB } \\
\text { O }\end{array}$ & $\begin{array}{l}35(19.4) \\
40(22.2) \\
31(17.2) \\
74(41.2)\end{array}$ & $\begin{array}{l}28(80) \\
37(92.5) \\
30(96.8) \\
62(83.8) \\
\end{array}$ & $\begin{array}{l}7(20) \\
3(7.5) \\
1(3.2) \\
12(16.2)\end{array}$ & $\begin{array}{l}1 \\
0.32 \\
0.13 \\
1\end{array}$ & $\begin{array}{l}-0.1-1.4 \\
0.01-1.15 \\
0.3-2.2\end{array}$ & & $\begin{array}{l}\mathrm{O} \\
\dot{1}\end{array}$ \\
\hline
\end{tabular}




\section{Discussion}

The prevalence of HM in this study was found to be $12.8 \%$, which was similar to the study done in Mexi$\mathrm{CO}^{15}$. However, the prevalence of $\mathrm{HM}$ in this study was higher than previously reported prevalence of HM that ranged between $0.3 \%$ and $3.4 \%$ in other countries. The difference could be because most of these studies were retrospective and their sample population involving only patients with gestational trophoblastic diseases ${ }^{2-6}$. In Uganda, the prevalence of CHM was found to be

$3.42 \%$ which is higher than what we found in our setting. The prospective study in Uganda involved patients with confirmed CHM clinically and histologically which could explain the difference ${ }^{16}$.

In this study, low extreme of maternal age was strongly associated with prevalence of HM $(p=0.01)$. This was consistent with findings observed in other studies ${ }^{9,17,18}$. However, contrarily to other studies which also showed the risk to be increased at an age above 40 years, such pattern was not observed in this study, possibly because in our community, by the age of 40 years, most women have completed their family. These contradicting findings underscore the need for conducting further studies involving a larger cohort of patients to establish an absolute link between HM and the advanced maternal age.

The findings of this study showed that the majority of the participants with HM were primiparous (15.8\%). Moreover, PHM (12.9\%) was more common than CHM (3\%). The risk of HM was found to decrease with an increase in the number of births, but this was not statistically significant. Similar result were reported in Italy by Parazzini et al but the trend in risk was significant only in $\mathrm{PHM}^{8}$. However, the current findings differ from those of Kumar et al, who reported the risk of $\mathrm{HM}$ to increase with parity ${ }^{19}$. This discrepancy could be explained by the fact that the age of majority of multiparous patients in the other studies was above 40 years, which is also reported to be a risk for HM.

The results obtained from this study showed $12.9 \%$ of HM among participants with history of contraceptive use (Table 2). Even though they were few in number $(47.2 \%)$, these findings still concurred with those previously reported by a study conducted in USA ${ }^{20}$. Moreover, a large number of participants in this study with the diagnosis of HM (12.6\%) had no history of contraceptive use, which may be a reason for lack of association between HM and history of contraceptive use $(p=0.95)$. These findings are different from those by Palmer et al partly because in their study they used a multicenter case control study specifically to establish the association of contraceptive use and $\mathrm{HM}^{20}$.

In this study, 35\% participants had history of previous abortion among who (14.3\%) had HM, while 65\% had no prior abortion but among them 12\% had HM. These findings are similar to those by Parazzini et al which showed that the risk of HM increases with history of previous abortion ${ }^{8}$. Spontaneous type of abortion has been found to be more associated with HM than induced abortion as was seen in a study done in Italy ${ }^{8}$. This was also reflected in this study in which $15.5 \%$ of participants with spontaneous abortion were diagnosed to have HM while none of the participant with induced abortion had HM.

Unlike other studies ${ }^{9,21}$, in this study there was no participant with previous history of HM. Previous history of HM could however not have been ruled out because in our settings it is not a standard practice to routinely histologically analyze every retained products of conception (RPOC) obtained after evacuation. Hence, there is a possibility that of the $35 \%$ of participant with previous history of abortion among which $14.3 \%$ had HM some could have HM in previous abortion.

In this study, of all participants with blood group ' $\mathrm{A}$ ' $20 \%$ were found to have HM. This was the highest percentage of $\mathrm{HM}$ as per blood groups. These findings are contrary to the study done by Lorigan et al which showed blood group 'B' to be predominant in cases with $\mathrm{HM}^{22}$. However, it is inconclusive to say that participants with blood group 'A' are at an increased risk of HM partly because both the study population and other risk factors for HM were not evenly distributed based on blood group.

\section{Conclusion}

The prevalence of HM was considerably high among patient with incomplete abortion attending Bugando Hospital and Sekou toure Hospital. Age between 15-20 years was found to be associated risk factor with diagnosis of HM. Submission of evacuated products of conception (POC) for histopathological analysis should be considered as the main strategy to know the causative factor of abortion. We also recommend analytical study to evaluate causal association and predictor of malignancy in patients diagnosed with HM.

\section{Acknowledgement}

The authors would like to thank all staff in the department of Obstetrics and gynecology at Sekou Toure Hospital and Bugando Medical Centre. 


\section{Authors' contributions}

$\mathrm{BK}, \mathrm{AM}, \mathrm{DM}, \mathrm{PR}$ and EK participated in the design of the work. BK participated in the collection of specimen and clinical data. PR analyzed the sample. EK analyzed and interpreted the data. BK and DM wrote the first draft of the manuscript which was approved by all authors.

\section{Competing interests}

The authors declare that they have no competing interests.

\section{References}

1. Seckl, M.J., N.J. Sebire, and R.S. Berkowitz. Gestational trophoblastic disease. Lancet, 2010. 376(9742): p. 717-29.

2. Lurain, J.R. Gestational trophoblastic disease I: epidemiology, pathology, clinical presentation and diagnosis of gestational trophoblastic disease, and management of hydatidiform mole. Am J Obstet Gynecol, 2010.

203(6): p. 531-9.

3. Biscaro, A., Silveira, S. K., Locks, G. D. F., Mileo, L. R., Silva Júnior, J. P. D., \& Pretto, P. Frequency of hydatidiform mole in tissue obtained by curettage. Rev Bras Ginecol Obstet, 2012. 34(6): p. 254-8.

4. Mbamara SU., Obiechina, N., Eleje, G. U., Akabuike, C. J., \& Umeononihu, O. S. Gestational trophoblastic disease in a tertiary hospital in Nnewi, southeast Nigeria. Nigeria Medical Journal, 2009. 50(4): p. 87-89.

5. Moodley, M., K. Tunkyi, and J. Moodley. Gestation- al trophoblastic syndrome: an audit of 112 patients. A South African experience. Int J Gynecol Cancer, 2003.

13(2): p. 234-9.

6. Smith, H.O. Gestational trophoblastic disease epidemiology and trends. Clin Obstet Gynecol, 2003. 46(3): p.

541-56.

7. Parazzini, F., C. La Vecchia, and S. Pampallona. Parental age and risk of complete and partial hydatidiform mole. Br J Obstet Gynaecol,1986. 93(6): p. 582-5.

8. Parazzini, F., Mangili, G., La Vecchia, C. A. R. L. O., Negri, E., Bocciolone, L., \& Fasoli, M. Risk factors for gestational trophoblastic disease: a separate analysis of complete and partial hydatidiform moles. Obstet Gynecol, 1991. 78(6): p. 1039-45.

9. Sebire, N.J., Foskett, M., Fisher, R. A., Rees, H., Seckl, M., \& Newlands, E. Risk of partial and complete hydatidiform molar pregnancy in relation to maternal age. BJOG, 2002. 109(1): p. 99-102.

10. Berkowitz R. S., Im, S. S., Bernstein, M. R., \& Gold- stein, D. P. Gestational trophoblasticdisease. Subsequent pregnancy outcome, including repeat molar pregnancy. $J$ Reprod Med, 1998. 43(1): p. 81-6.

11. Sebire, N.J., Fisher, R. A., Foskett, M., Rees, H., Seckl, M. J., \& Newlands, E. S. Risk of recurrent hydatidiform mole and subsequent pregnancy outcome following complete or partial hydatidiform molar pregnancy. BJOG, 2003. 110(1): p. 22-6.

12. Acaia, B., Parazzini, F., La Vecchia, C., Ricciardiello, O., Fedele, L., \& Battista Candiani, G. Increased frequency of complete hydatidiform mole in women with repeated abortion. Gynecol Oncol, 1988. 31(2): p. 310-4.

13. Horn, L.C., M. Rosenkranz, and K. Bilek. The value of placental histology for the detection of genetically-induced abortions. Z Geburtshilfe Perinatol, 1991. 195(2): p. 47-53.

14. Kish, L., ed. Survey sampling. 1965, John Wiley \& Sons, Inc.: New York.

15. Romero Gutierrez, G., Barón, V. S., Avecilla, H. A., \& Ponce, D. L. A. Unsuspected molarpregnancy in first trimester miscarriages. Ginecol Obstet Mex, 2003. 71: p.

55-9.

16. Kaye, D.K., Gestational trophoblastic disease following complete hydatidiform mole in Mulago Hospital, Kampala, Uganda. Afr Health Sci, 2002. 2(2): p. 47-51.

17. Loukovaara, M., Pukkala, E., Lehtovirta, P., \& Leminen, A. Epidemiology of hydatidiform mole in Finland, 1975 to 2001. Eur J Gynaecol Oncol, 2005. 26(2): p.

207-8.

18. Salehi, S., Eloranta, S., Johansson, A. L., Bergström, M., \& Lambe, M. Reporting and incidence trends of hydatidiform mole in Sweden 1973-2004. Acta Oncol, 2011. 50(3): p. 367-72.

19. Kumar, N., Saxena, Y. K., Rathi, A. K., Chitra, R., $\&$ Kumar, P. Host and risk factors for gestational trophoblastic disease: a hospital-based analysis from India. Med Sci Monit, 2003. 9(10): p. CR442-7.

20. Palmer JR., Driscoll, S. G., Rosenberg, L., Berkowitz, R. S., Lurain, J. R., Soper, J., et al., Oral contraceptive use and risk of gestational trophoblastic tumors. Journal of National Cancer Institute, 1999. 91(7): p. 635-640.

21. Steigrad, S.J., Epidemiology of gestational trophoblastic diseases. Best Pract Res Clin Obstet Gynaecol, 2003.

17(6): p. 837-47.

22. Lorigan, P.C., Sharma, S., Bright, N., Coleman, R. E., \& Hancock, B. W. Characteristics of women with recurrent molar pregnancies. Gynecol Oncol, 2000. 78(3 Pt 1): p. 288-92. 